\title{
Microcracking and shear fracture in ice
}

\author{
M. A. Rist, S.J. Jones and T. D. Sl.ade \\ Institute for Marine Dynamics, National Research Council, P.O. Box 12093, St John's, Newfoundland A1B 3T5, Canada
}

\begin{abstract}
The relationship between microcracking and ice strength has been examined using triaxial apparatus in which crack damage can be inhibited by the imposition of confining pressure. Shear fracture in ice is observed to be a rapid, unstable process with no apparent indication of tensile crack localisation or interaction prior to failure and no accompanying large-scale volumetric changes, at least to within $1 \mathrm{~ms}$ of the occurrence of macroscopic failure. Shear fracture strength displays little or no dependence on confinement at moderate pressures $(\mathrm{P}=5-20 \mathrm{MPa})$, and there is no evidence of significant crack sliding before macroscopic fracture under these conditions. Where flow with distributed microcracking occurs, yield strength can also remain remarkably unaffected by confining pressure, despite reduced crack damage. Particularly under conditions where microcracks are induced by predominantly elastic strains, they may remain stable and non-interacting even at high volumetric densities.
\end{abstract}

\section{INTRODUCTION}

It is frequently observed that ice retains uncommonly brittle behaviour at high homologous temperatures when compared to other polycrystalline materials. Indeed, on the grain-boundary level much consideration has been given to the mechanism underlying microcrack formation due to localised tensile stresses, the process being attributed to grain-boundary sliding (Sinha, 1984), dislocation pile-up (Schulson and others, 1984; Cole, 1988) or crystal elastic anisotropy Cole, 1988; Sunder and $\mathrm{Wu}, 1990)$. On the macroscopic level, tensile fracture is readily explained since it is considered to occur as the result of the unstable propagation of a single crack previously formed by one of the above mechanisms. On the other hand, the nature of macroscopic brittle fracture and failure under an overall compressive field is rather poorly understood. Although cracks in ice are known to nucleate in compression due to localised tension, it is not clear how they propagate or interact to cause ultimate failure. Part of the problem has been that the commonly used uniaxial compression test has provided a range of failure modes including axial splitting, shear fracture, explosive fracture or a mixture of these modes, depending frequently on the non-uniformity of the imposed stress near the specimen-machine interface. A practical means of applying a more uniform state of stress is provided by the triaxial test, widely employed in the experimental examination of brittle rocks, in which a hydrostatic pressure and a uniaxial stress are superimposed (principal stresses $\left.\sigma_{1}>\sigma_{2}=\sigma_{3}\right)$. Where brittle ice fracture has been investigated using this technique, failure occurs by the formation of a single distinct shear fault (Durham and others, 1983; Murrell and others, 1991). Failure of this type is frequently observed, for example, in association with other mechanisms under the complex stress states that occur during high deformation rate interactions between ice floes and offshore structures.

Triaxial testing also provides a means of investigating the influence of microcracking on ice ductile deformation, provided tests are not conducted too near the pressure melting point, since hydrostatic pressure inhibits crack formation but has a minimal effect on plastic flow. Here we present results from triaxial tests that provide insight into the nature of microcracking as it affects ice strength and the shear fracture process.

\section{GENERAL POLYGRYSTALLINE SHEAR FRACTURE}

The mechanics of shear fracture in polycrystalline materials under compression has received particular attention with respect to the failure of brittle rocks, for which a wide body of theoretical and experimental work exists (Paterson, 1978; Jaeger and Cook, 1979; Scholz, 1990). Brittle failure has been found to be strongly dependent on confining pressure and for this reason is commonly investigated using triaxial testing. Shear fracture development is considered to be a very complex process involving the growth and interaction of tensile microcracks (Wawersik and Brace, 1971; Hallbauer and others, 1973), the complexity arising because it appears that an inclined crack does not propagate by shear in its own plane in a brittle isotropic medium. Even under allround compression a sliding crack will tend to form mode I (tensile) extensions that align themselves in the direction of the maximum principal stress, parallel to $\sigma_{1}$ (Ashby and Hallam, 1986). However, only under uniaxial stress, or with very small confining pressures, is brittle compressive failure sometimes observed to occur by unstable crack growth in this direction ("axial split- 
ting"). Rather, shear fracture occurs, and is seen as the result of interacting grain-sized microcracks which form a broad anisotropic process zone in which shear failure can develop. Although the final stage of this process is not well understood, attempts have been made to model the general behaviour using damage mechanics, either by simply considering axial growth driven by local tensile deviatoric stresses (e.g. Costin, 1983) or by considering out-of-plane wing-crack extensions caused by crack sliding (e.g. Sammis and Ashby, 1986; Kemeny and Cook, 1987). In either case, large dilatant volumetric changes are expected due to crack opening and interaction as failure is approached, and experiment indicates that initially randomly distributed cracks coalesce to form a shear band near peak stress (e.g. Hallbauer and others, 1973).

\section{EXPERIMENTAL METHODOLOGY}

To examine the influence of microcracking on ice failure we have conducted tests on specimens of pure isotropic polycrystalline (granular) ice using a purpose-built low temperature triaxial cell, illustrated in Figure 1. The apparatus comprises a stainless steel pressure vessel with a pressure compensated piston arrangement and large removable end caps which aid access to the test specimen and internal load cell. The system utilises clear silicone oil to impose hydrostatic confining pressures up to $20 \mathrm{MPa}$ whilst an extra axial load is applied via the piston to deform the specimen, which may be cylindrical or

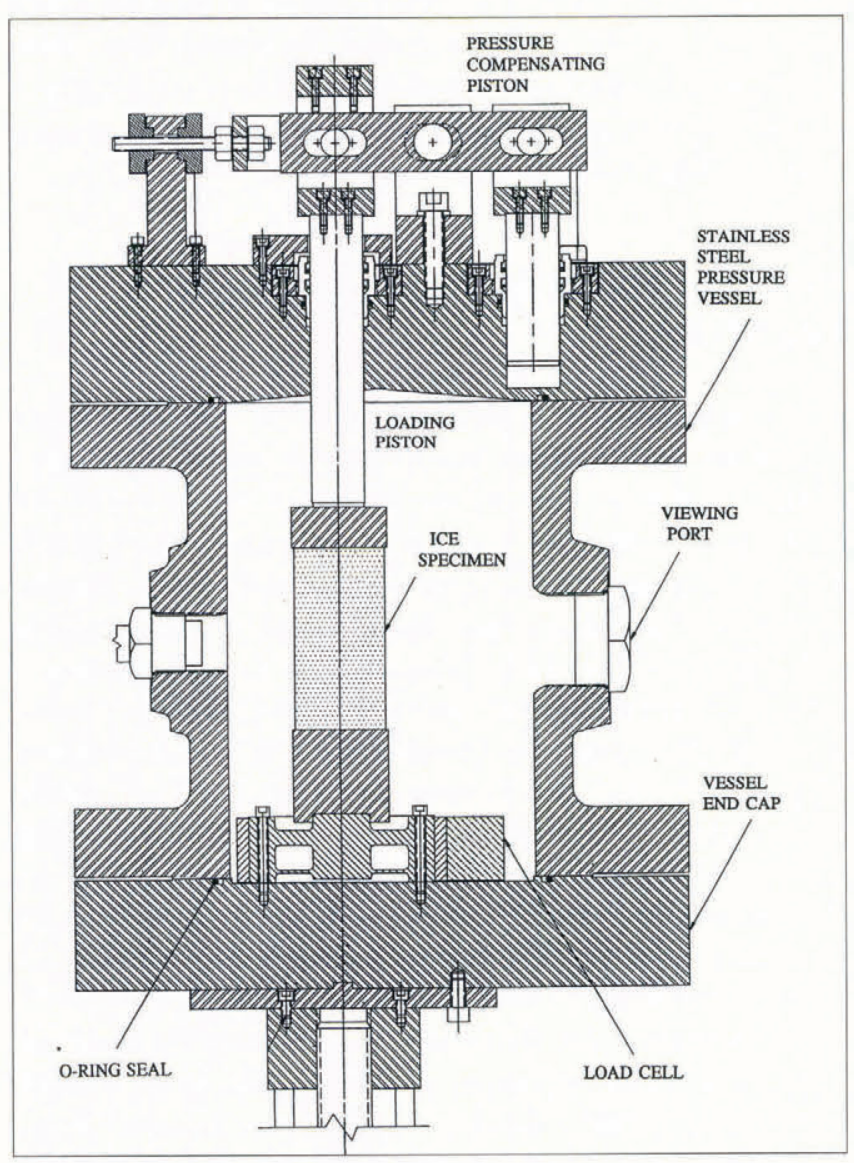

Fig. 1. Scale diagram of the triaxial cell in cross-section. The ice specimen shown is $60 \mathrm{~mm}$ wide. rectangular. In effect, a compressive stress $\sigma_{1}$ is applied along the long axis of the specimen under confining pressure $\mathrm{P}=\sigma_{2}=\sigma_{3}$ and the imposed differential stress in the axial direction is $\left(\sigma_{1}-\sigma_{3}\right)$. The cell also incorporates viewing ports for direct observation of ice specimens during deformation. Nominal test temperature $\left(-20^{\circ} \mathrm{C}\right.$ for this study) was maintained by adjusting the ambient temperature of the cold room in which the cell was contained, adequate stability $\left( \pm 0.2^{\circ} \mathrm{C}\right)$ being ensured by the thermal mass of the steel pressure vessel.

Ice samples were manufactured by flooding vacuumed moulds, containing sieved ice seeds, with de-aerated water to produce ice consisting of randomly oriented grains of uniform size. Rectangular specimens were used to aid visual observation and transducer attachment; comparison with cylindrical specimens appears to indicate no influence of this specimen geometry on failure mode. Dimensions were $60 \times 60 \times 120 \mathrm{~mm}$ and the mean grain diameter was approximately $5 \mathrm{~mm}$ as estimated by counting the number of grains per unit area in planar cross-section and assuming uniform grains of spherical geometry. Bulk specimens contained no large bubbles but had an overall hazy appearance and a density of $912 \pm 3 \mathrm{~kg} \mathrm{~m}^{-3}$. Meltwater conductivity of the ice was $\approx 2 \times 10^{-4} \mathrm{~S} \mathrm{~m}^{-1}$.

Constant specimen strain rate in the direction of the loading axis was maintained by averaging the signal, within a servo-control loop, from two LVDTs embedded directly into opposite faces, parallel to the long axis of the ice specimen, using small aluminium grips. Lateral strain, perpendicular to the direction of loading, was measured using one or two transducers (depending on whether viewing access was required) similarly placed on the short specimen faces. Gauge lengths were $60 \mathrm{~mm}$ axially and $30 \mathrm{~mm}$ laterally, so that strains were measured in the central portion of the specimen where the applied stress was most uniform.

\section{ICE SHEAR FRACTURE}

\section{Deformation behaviour}

At $-20^{\circ} \mathrm{C}$ with a strain rate of $10^{-2} \mathrm{~s}^{-1}$ it was found that the $5 \mathrm{~mm}$ grain-sized polycrystalline ice samples used in this study failed in a brittle manner due to the abrupt formation of a macroscopic shear fracture oriented at about $45^{\circ}$ to the direction of the loading axis. Typical behaviour is shown in Figure 2 for a specimen deformed under $10 \mathrm{MPa}$ confinement (in this and other figures, the differential stress, $\sigma_{1}-\sigma_{3}$, is shown). At the onset of initial fracture, coinciding with the peak stress, the servohydraulic apparatus was incapable of responding to extremely rapid structural changes occurring within the specimen. Examination of Figure 2 shows that this caused the loading piston at first to overshoot as sliding occurred along the failed fracture surface, and then to compensate by withdrawing, thus allowing the load to drop almost to zero. Following this, with control regained, the apparatus reloaded the specimen until the static frictional force between the two pieces of broken ice was overcome - the overall result being a kind of stick-slip loading curve as this process was repeated several times. The magnitude of 


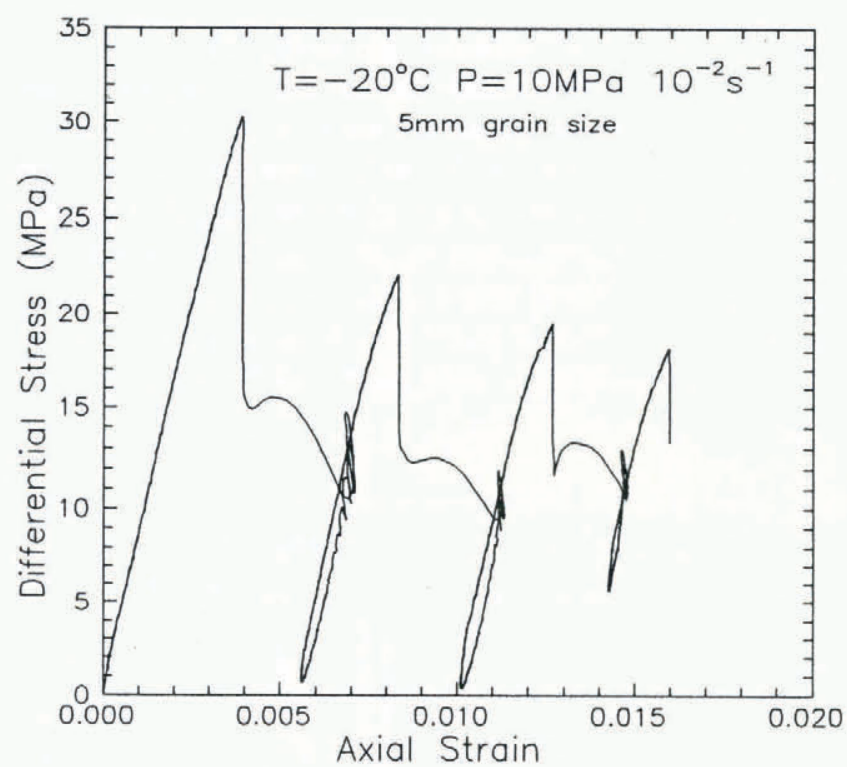

Fig. 2. Typical brittle fracture stress-strain curve for ice under triaxial stress, including post-failure stick-slip sliding on the inclined fracture surface.

the post-failure stresses was strongly influenced by confinement, implying a coefficient of static friction dependent on confining pressure (Figure $3 ; \mu \approx 0.2$ $0.5)$. The sliding phenomenon is significant not only because it demonstrates the large post-failure stresses that can be sustained by fractured ice when it is under confining pressure, but also, remarkably, that the confining fluid has not permeated the unprotected specimen.

In contrast, Figure 3 shows that the shear fracture strength displayed little or no dependence on confining pressure over the stress range examined, indicating that the underlying fracture mechanism does not require that static ice frictional forces, for example on closed crack faces, must be overcome.

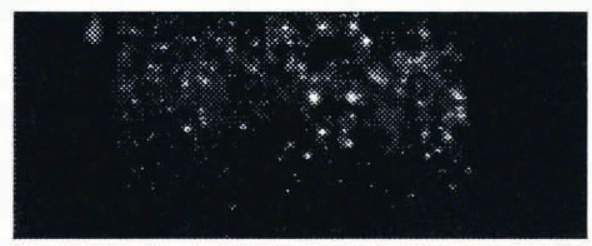

I. $\mathrm{t}=0.2140 \mathrm{~s}, \sigma=14.4 \mathrm{MPa}, \epsilon=0.171 \%$

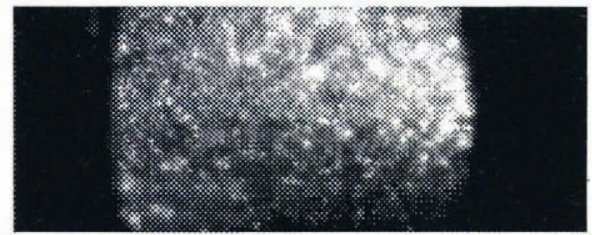

III. $\mathrm{t}=0.4140 \mathrm{~s}, \sigma=29.5 \mathrm{MPa}, \epsilon=0.376 \%$

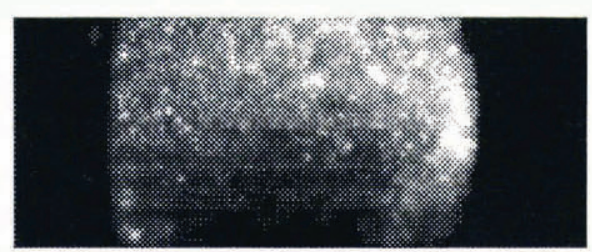

V. $\mathrm{t}=0.7140 \mathrm{~s}, \sigma=30.3 \mathrm{MPa}, \epsilon=0.391 \%$

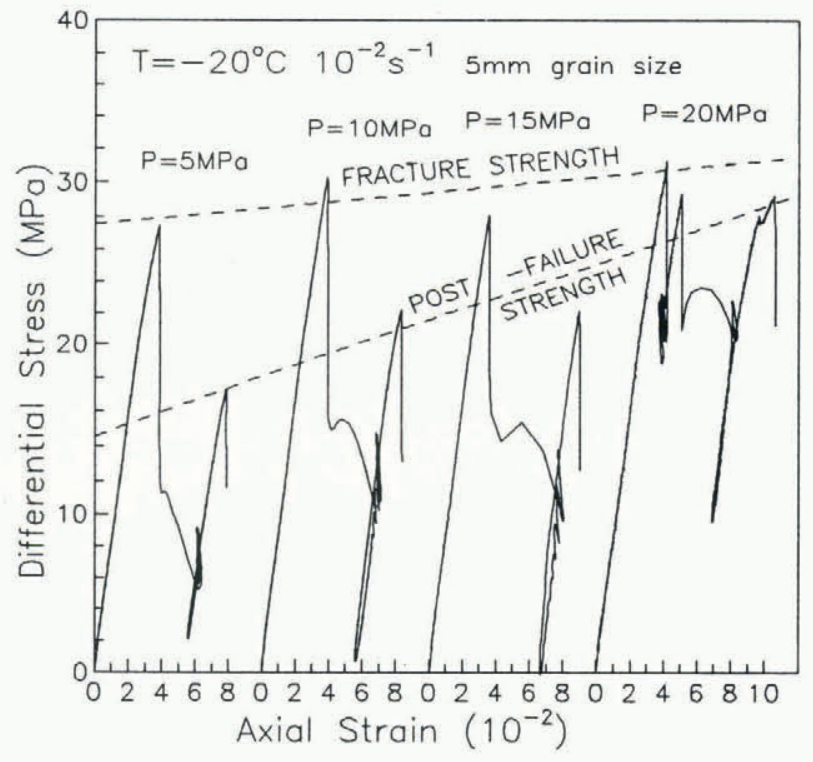

Fig. 3. Series of brittle fracture deformation curves at various confining pressures showing the dependence of strength and post-failure sliding on the imposed confinement.

Thin section examination of the fractured ice revealed that the fault zone was quite narrow, often less than one grain diameter, even after sliding, and contained small pulverised grains which may have been the result of the post-failure deformation. In fact, very little damage could be observed elsewhere in the specimen indicating extensive crack healing after the confining pressure was removed.

\section{High speed video recording and volumetric measurements}

In order to come to a better understanding of the role of microcracking in the shear fracture process, direct observations were made of specimens during deform-

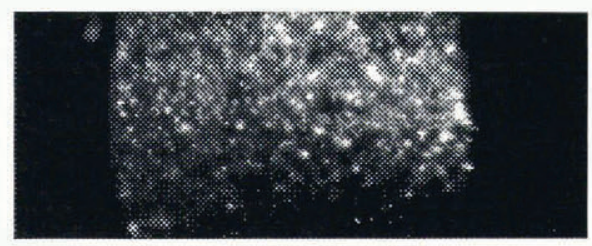

II. $\mathrm{t}=0.3140 \mathrm{~s}, \sigma=22.3 \mathrm{MPa}, \epsilon=0.273 \%$

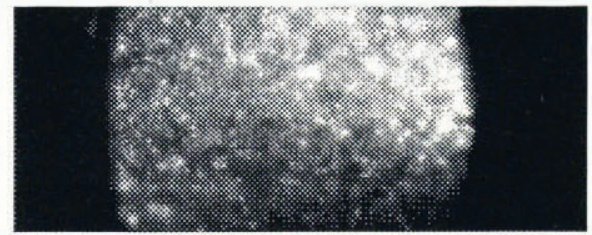

IV. $\mathrm{t}=0.7135 \mathrm{~s}, \sigma=30.3 \mathrm{MPa}, \epsilon=0.391 \%$

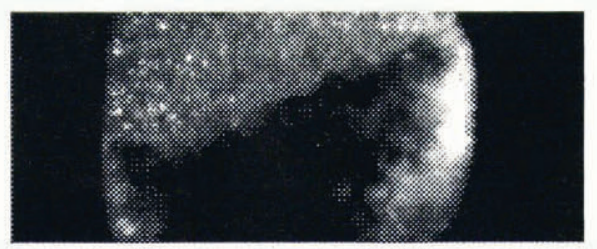

VI. $\mathrm{t}=0.7145 \mathrm{~s}, \sigma=27.9 \mathrm{MPa}, \epsilon=0.393 \%$

Fig. 4. Digital images of specimen damage recorded at intervals during brittle fracture as indicated in Figure 5. 


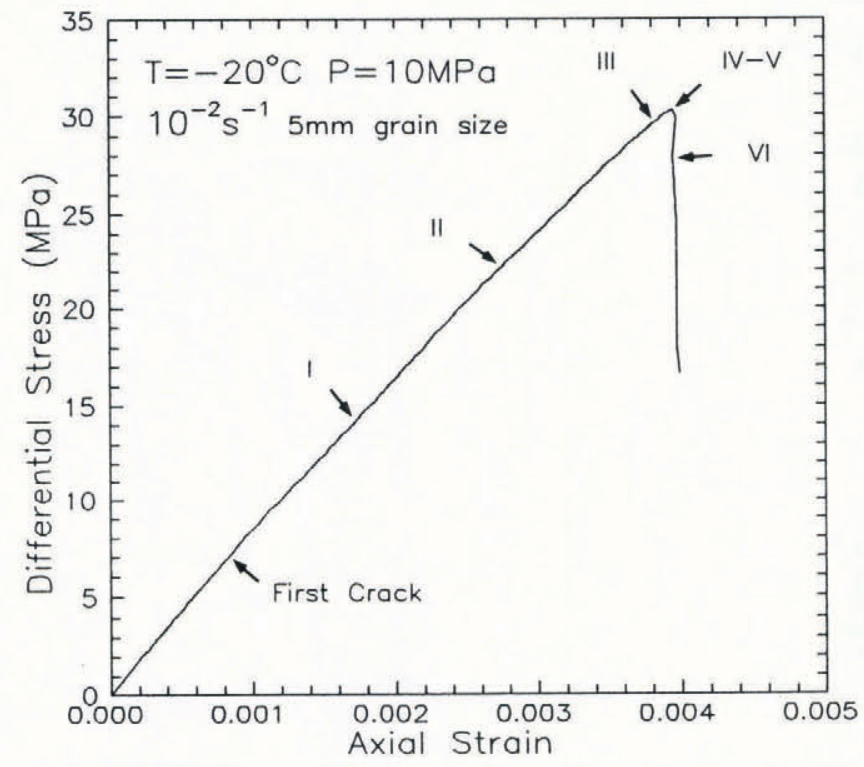

Fig. 5. Brittle stress-strain history showing the relationship between deformation and the images presented in Figure 4.

ation. Since, at the high strain rates used here, failure was reached in less than $0.5 \mathrm{~s}$, a high-speed video camera was used to record digital images at the rate of 2000 frames per second. Visible microcracks that nucleate in ice under loading are of the order of one grain size in length and preferentially oriented along the most compressive stress axis under both uniaxial and triaxial stress (Kalifa and others, 1989; Rist and Murrell, 1994). For the purpose of illuminating these grain-sized microcracks as they nucleated, the specimen was strongly lit from either side but not from behind. The camera aperture and lighting were adjusted so that the specimen appeared entirely dark at the commencement of loading. As microcracks formed they reflected light into the camera lens so that the grainsized flaws appeared as distinct individual bright entities, at least in the early stages of deformation. Images recorded during the progress of one such test conducted at $-20^{\circ} \mathrm{C}$ with a strain rate of $10^{-2} \mathrm{~s}^{-1}$ under $10 \mathrm{MPa}$ confinement are shown in Figure 4, and their relationship with the specimen stress-strain history is indicated in Figure 5. The images of Figure 4 show the central onethird of a $60 \mathrm{~mm}$ wide rectangular specimen; the barrelling is an optical illusion created by the thick laminated quartz glass window necessary to withstand the imposed confining pressure. The lowermost visible section of the specimen appears somewhat darker, particularly in the early images, because the lighting is slightly off centre, not because the microcracking is any less dense. A bright mark near the upper lefthand side of the specimen, also most apparent in the early images, is a reflection from one of the displacement transducers.

The first crack was observed at an applied differential stress of $6.9 \mathrm{MPa}$ after $0.079 \%$ axial strain. Images I-III indicate the progress of microcrack damage up to the peak stress. It is difficult to make a precise estimate of the microcrack density at any particular stage of deformation, however there are at least 100 bright entities in the adequately lit upper half of image II. This number corresponds to about 1000 ice grains assuming uniform
$5 \mathrm{~mm}$ diameter and spherical geometry. Hence a lower limit estimate for the crack density in this image is one crack for every 10 grains. Kalifa and others (1992) observe crack densities of the order of one crack per grain associated with ductile failure of ice in triaxial compression at $-10^{\circ} \mathrm{C}$ with lower strain rates and correspondingly lower stresses. Hence there is no evidence that particularly high crack densities have been produced in the high strain-rate fracture tests presented here.

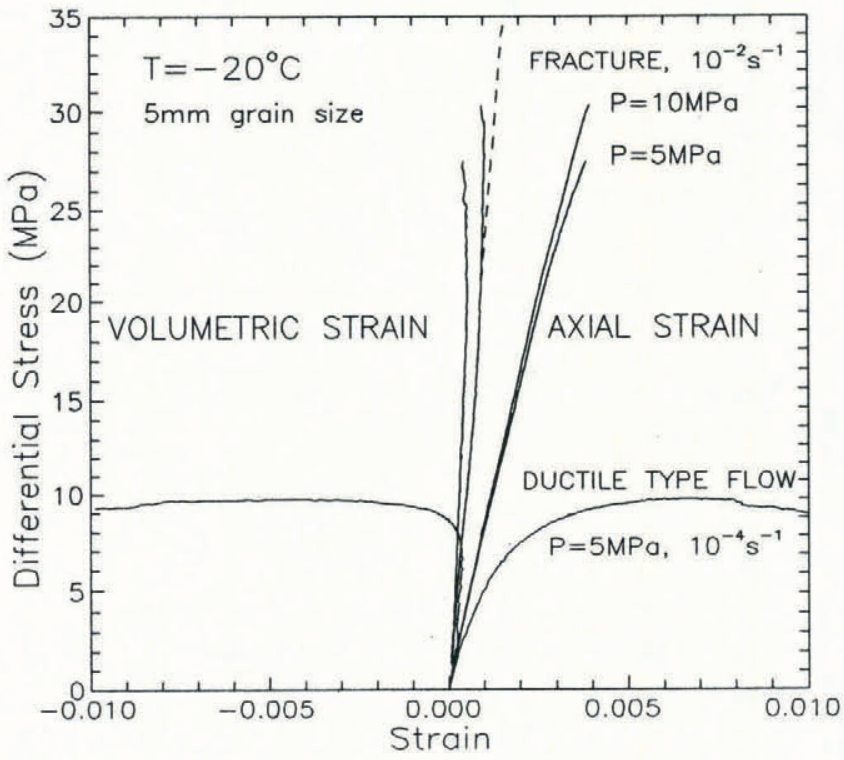

Fig. 6. Axial and volumetric strains measured for specimens during shear fracture and ductile type flow al fixed axial strain rate. The dashed line indicates purely elastic behaviour (compression is positive).

The non-elastic (dilatant) volume change in specimens loaded to failure under confining pressure at the $10^{-2} \mathrm{~s}^{-1}$ strain rate was found to be very small. Figure 6 shows the volumetric measurements for the fracture test at $\mathrm{P}=10 \mathrm{MPa}$ described above. The change in volume barely deviates from that expected for purely elastic deformation of fully dense ice (shown by the dashed line in Figure 6, assuming $\mathrm{E}=9 \mathrm{GPa}, \nu=0.3)$. For comparison, the results from a similar fracture test with a lower $5 \mathrm{MPa}$ confinement are also shown, indicating that dilatancy is sensitive to confining pressure. This behaviour contrasts sharply with the volumetric changes associated with ductile-type failure of polycrystalline ice in which yield and flow are accompanied by distributing microcracking, but no macroscopic fracture surface develops. An example of this behaviour is also shown in Figure 6 for ice deformed at a lower strain rate of $10^{-4} \mathrm{~s}^{-1}$. The volumetric strain accompanying the attainment of peak stress is an order of magnitude greater than that observed for fracture at the higher strain rate, despite much lower stresses, indicating that large-scale crack opening or crack interaction may have taken place, or that many more cracks have formed.

Shear fracture formation in ice appears to be extremely rapid. This is illustrated by the three consecutive images IV-VI in Figure 4, taken at intervals of $0.5 \mathrm{~ms}$, coinciding with fault propagation. Image IV, 
immediately before failure, shows no hint of large-scale fracture or crack localisation; image $\mathrm{V}$ captures the growth of the failure surface in the form of a dark shadow emanating from low down on the far side of the specimen; in image VI growth is complete and the shear fracture has intersected with the near side of the specimen. The entire process is over in less than $1 \mathrm{~ms}$, implying a propagation velocity of at least $100 \mathrm{~ms}^{-1}$. The volumetric measurements associated with fracture, presented in Figure 6, were recorded at a frequency of $4000 \mathrm{~Hz}$ and also fail to indicate any distinct change in dilatancy, which might indicate fault formation, immediately prior to failure.

\section{Fracture of damaged ice}

A further attempt was made to clarify the influence of microcracking on brittle shear fracture by pre-damaging ice before testing to failure. Microcrack damage was incorporated by loading at high strain rate to approximately $80-85 \%$ of the expected peak stress and unloading. The intention was to introduce microcracking using predominantly elastic strains, so that flaws were introduced but little permanent creep damage had occurred, sufficient time also being allowed after each loading for most of the delayed elastic strain to relax.

The results from one such series of tests, conducted under identical experimental conditions to that for which high-speed images were presented in the previous section, is shown in Figure 7 . At $-20^{\circ} \mathrm{C}$ with a confining pressure of $10 \mathrm{MPa}$ the specimen was loaded through several cycles at $10^{-2} \mathrm{~s}^{-1}$, the most severe of which are shown in the figure (the previous two cycles involved peak differential stresses of $5 \mathrm{MPa}$ and $10 \mathrm{MPa}$ at identical loading rates). In the last cycles before fracture, a differential stress of about $25 \mathrm{MPa}$ was applied, with microcrack damage corresponding approximately to that shown in image II of Figure 4. The behaviour displays an interesting hysteresis effect with virtually all of the axial strain regained after $1000 \mathrm{~s}$. Although the initial loading curve departs from linear elastic behaviour even at low stresses,

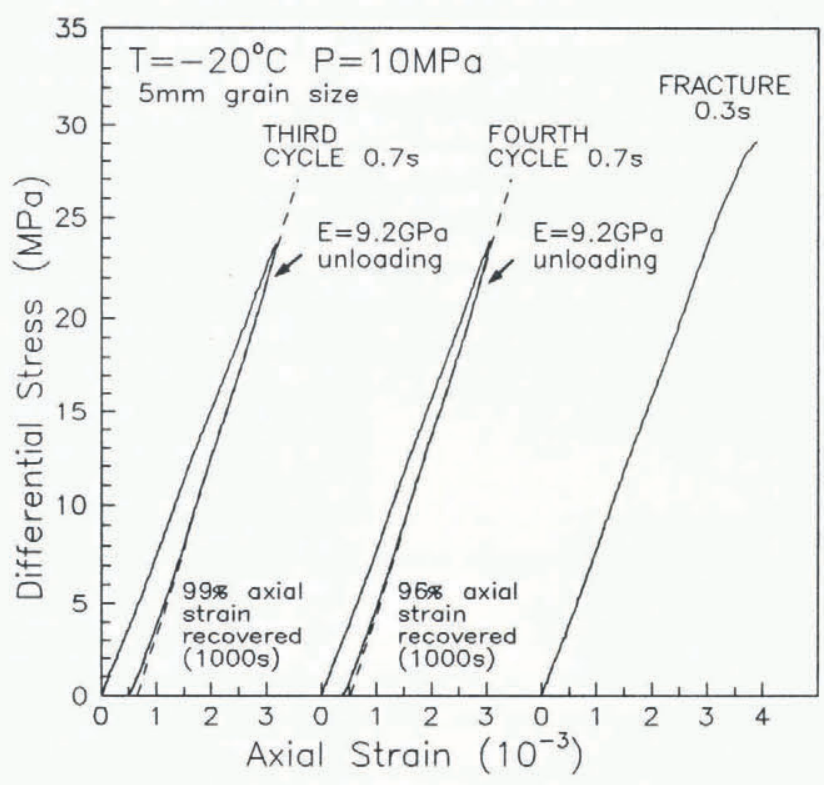

Fig. 7. Effect of repeal loading to high stresses on ice brittle deformation behaviour under triaxial stress. the initial portion of the unloading curve corresponds closely with the elastic modulus of entirely intact ice. The intrinsic elastic behaviour of our laboratory ice was established by similar unloading tests on undamaged samples at lower stresses and found to be $9.1 \pm 0.1 \mathrm{GPa}$. (In contrast, tests on bubbly natural iceberg ice produced $\mathrm{E} \approx 7 \mathrm{GPa}$.)

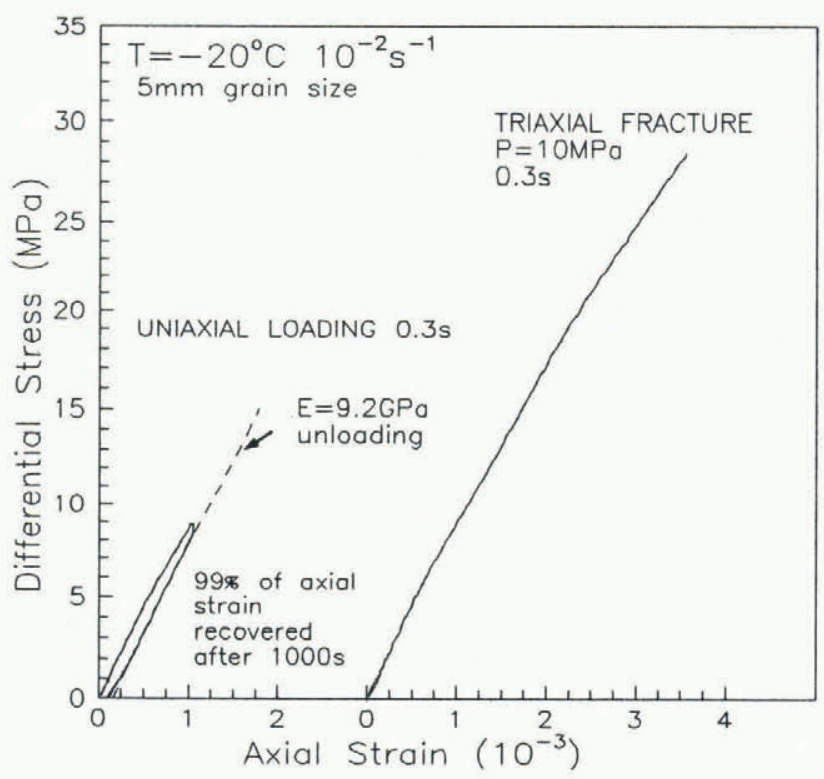

Fig. 8. Repeat loading using uniaxial deformation to induce damage before loading to fracture under triaxial stress.

We have also damaged samples under uniaxial stress to $80 \%$ of their expected peak load (Fig. 8) in an attempt to induce more open cracking. The same hysteresis effect and high modulus were observed on unloading. Subsequent application of confining pressure and loading to failure again indicates no effect on fracture strength or behaviour.

It is worth noting at this point that the specimens used here were unprotected from the pressurised silicone oil confining medium, sometimes for over an hour in a damaged state during repeat loading. The fact that there is no evidence of weakening due to penetration of the oil may be indicative of the closed, non-interacting nature of the flaws.

\section{MICROCRACKING AND DUCTILE FLOW STRENGTH}

It is widely considered that microcracking enhances flow and decreases the yield strength of previously intact ice. The ductile strength of ice can be considered as a temperature- and rate-sensitive yield stress and only by imposing a confining pressure to inhibit crack formation and growth without altering the plastic flow behaviour can the influence of microcracking be isolated. Figure 9 shows examples from a series of triaxial tests conducted at $20^{\circ} \mathrm{C}$ on jacketed cylindrical samples of $1 \mathrm{~mm}$ grain size in which it was found that ice strength was independent of confining pressure above $\mathrm{P}=5 \mathrm{MPa}$, despite the presence 


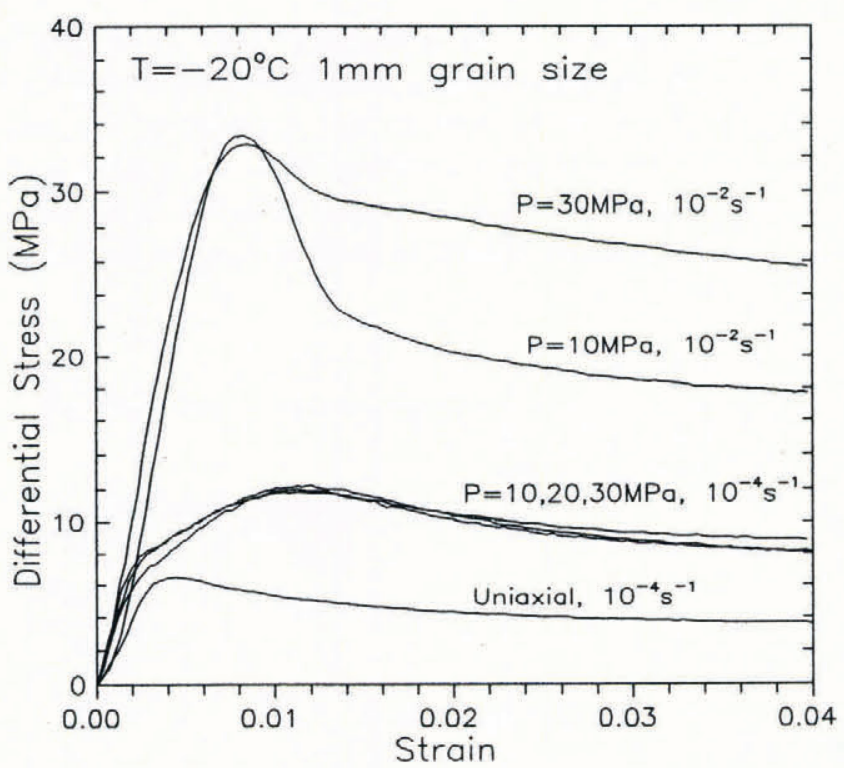

Fig. 9. Influence of confining pressure on ice ductile flow and yield strength.

of often dense microcracking (see Murrell and others, 1991; Rist and Murrell, 1991, 1994). Although intense cracking under uniaxial conditions does cause weakening, the tests conducted at $10^{-4} \mathrm{~s}^{-1}$ shown in the figure indicate that the imposition of even a moderate confining pressure inhibits cracking activity to the extent that strength and even overall behaviour is unaffected (the weakest distribution of cracks in these tests was for the $10^{-4} \mathrm{~s}^{-1} / \mathrm{P}=$ $30 \mathrm{MPa}$ specimen which contained scattered grain-sized axially aligned cracking; the $10^{-4} \mathrm{~s}^{-1} / \mathrm{P}=10 \mathrm{MPa}$ specimen was opaque with microcracks). Similarly, the effect of confining pressure on the $10^{-2} \mathrm{~s}^{-1}$ specimens, which were both densely cracked, was to reduce the post-failure stress drop, not to alter the yield strength. The maximum imposed mean normal stress at failure in these tests was about $40 \mathrm{MPa}$, enough to lower the pressure-melting point by about $4^{\circ} \mathrm{C}$, but insufficient to alter the flow properties significantly.

\section{DISCUSSION}

Several features associated with shear fracture in ice make it an unusual phenomenon. The brittle compressive failure strength of a polycrystalline solid is normally expected to be strongly dependent on confining pressure but ice shear fracture displays little or no pressure dependence at $-20^{\circ} \mathrm{C}$ with $\mathrm{P}>5 \mathrm{MPa}$ (Fig. 3). Pressure independence of ice brittle shear strength has also been observed at $-40^{\circ} \mathrm{C}$ for confining pressures above $10 \mathrm{MPa}$ (Murrell and others, 1991; Rist and Murrell, 1994) and at temperatures between -115 and $-196^{\circ} \mathrm{C}$ when the confinement is above $50 \mathrm{MPa}$ (Durham and others, 1983). The $45^{\circ}$ fracture orientation is also unusual, occurring in the direction of maximum shear stress, and is accompanied by a very narrow fault zone. Brittle failure does not appear to be associated with any large-scale volumetric changes within the specimen and neither has it been possible to identify any evidence of crack coalescence or shear localisation preceding failure, either from thin section examination or from high-speed video observations.

The pressure independence points to a mechanism that does not depend on a critical crack density and other aspects of the failure process outlined above appear at odds with the notion of interacting tensile microcracks forming a broad damaged process zone. It is also interesting to note that the ductile yield strength for $1 \mathrm{~mm}$ grain-sized ice deformed at $10^{-2} \mathrm{~s}^{-1}$ shown in Figure 9 is close to the fracture strength of the $5 \mathrm{~mm}$ grain-sized specimens illustrated in Figure 3. Some of these observations may be resolved by speculating that the fracture process is triggered by localised plasticity, thus explaining the almost volume-conserving deformation, the pressure independence of strength and the direction of fracture that maximises the shear stress, although such a mechanism would be unprecedented. On the other hand, even though it has been demonstrated that the shear fracture surface in ice propagates at least as fast as $100 \mathrm{~m} \mathrm{~s}^{-1}$, this is still an order of magnitude slower than the measured tensile crack propagation speed $\left(1000 \mathrm{~m} \mathrm{~s}^{-1}\right.$; Sato and Wakahama, 1980) and does not preclude extremely rapid localised tensile microcrack growth and interaction immediately prior to fracture.

The reloading tests on damaged ice also provide insight into the nature of microcracking and in this respect the hysteresis effect observed in Figure 7 is particularly informative. Closed sliding cracks, as well as open cracks or flaws, are known to lower the effective modulus of polycrystalline materials. In fact, similar behaviour to that illustrated by the loading-unloading curves in Figure 7 is observed in some brittle polycrystalline rocks where the elastic modulus is reduced during loading by the presence of closed microcracks that undergo sliding. Such cracks only slide in the opposite sense after the load has dropped sufficiently to overcome friction in the reverse direction, producing a high modulus on initial unloading (Walsh, 1965). However, such materials contain randomly oriented flaws and display significant permanent strains once the load is removed because the frictional stresses that delay reverse sliding also prevent all the microcracks from returning to their original relative positions. The predominant alignment of cracking in the direction of loading commonly observed during compression testing of ice, and the large stresses needed to induce sliding (see Fig. 3), as well as the absence of significant permanent axial deformation, make this an unlikely scenario here. Instead, it is suggested that the larger region of purely elastic behaviour during unloading is a consequence of the directionality of ice anelastic behaviour (see Duval and others, 1983). It can be concluded that no significant crack sliding has occurred and the non-linearity during loading under these conditions is due almost entirely to the contribution from a delayed elastic strain component, not due to microcracking. This conclusion is reinforced by the near identical behaviour during repeat loading to ultimate fracture (Fig. 7) which occurs at the same high stress as for undamaged ice.

Although other workers have reported a significant influence of damage on ice deformation behaviour, it is important to point out that not all of this may be due to presence of microcracks per se. Stone and others (1989), 
for example, induced damage by deforming at low strain rate past the upper yield stress to $2 \%$ strain. Under these conditions it is likely there will have been extensive permanent plastic deformation of the ice crystals as well as crack formation, crack growth, crack interaction and maybe even grain rotation leading to large volumetric deformations as illustrated in Figure 6. From this it is difficult to isolate the influence of the presence of microcracks alone. The results presented here indicate that where microcrack damage is induced without significant permanent creep strains, subsequent stressstrain behaviour may be indistinguishable from that observed during deformation of undamaged ice.

\section{SUMMARY AND CONGLUSIONS}

An experimental examination of microcracking and shear fracture at high strain rates in ice has led to the following conclusions:

- the shear failure process is very rapid and proceeds through polycrystalline ice in compression at least as fast as $100 \mathrm{~m} \mathrm{~s}^{-1}$.

- shear fracture strength displays little or no pressure dependence under moderate confinement even though static frictional forces between sliding ice surfaces are strongly influenced by confining pressure.

- no large-scale volumetric changes are observed to precede shear fracture and no evidence has been found to indicate crack coalescence or localisation prior to failure.

- microcracks remain closed (or do not open significantly) but show no evidence of significant sliding before failure occurs.

Although the above observations do not preclude tensile crack interaction at a very late stage to form the observed shear fracture, they can also be explained by speculating that the unusual shear fractures observed here may have been triggered by localised plastic instability.

Generally, it appears that when microcrack damage is induced by predominantly elastic strains the cracks may remain remarkably stable and non-interacting even at high stresses. Where ductile deformation occurs by yield with distributed cracking, the presence of microcracks does not necessarily influence the failure stress, even at high volumetric densities.

\section{REFERENGES}

Ashby, M.F. and S.D. Hallam. 1986. The failure of brittle solids containing small cracks under compressive stress states. Acta Metall., 34, 497-510.

Cole, D. M. 1988. Crack nucleation in polycrystalline ice. Cold Reg. Sci. Technol., 15 (1), 79-87.
Costin, L.S. 1983. A microcrack model for the deformation of and failure of brittle rock. F. Geophys. Res., 88(B11), 94859492.

Durham, W.B., H.C. Heard and S.H. Kirby. 1983. Experimental deformation of polycrystalline $\mathrm{H}_{2} \mathrm{O}$ ice at high pressure and low temperature: preliminary results. J. Geophys. Res., 88, Suppl., Pt. 1, B377-B392.

Duval, P., M.F. Ashby and I. Andermann. 1983. Rate-controlling processes in the creep of polycrystalline ice. J. Phys. Chem., 87(21), $4066-4074$.

Hallbauer, D. K., H. Wagner and N.G.W. Cook. 1973. Some observations concerning the microscopic and mechanical behaviour of quartzite specimens in stiff, triaxial compression tests. Int. J. Rock Mech. Min. Sci. Geomech. Abstr., 10, 712-726.

Jaeger, J. C. and N. G. W. Cook. 1979. Fundamentals of rock mechanics. London, Chapman and Hall.

Kalifa, P., P. Duval and M. Ricard. 1989. Crack nucleation in polycrystalline ice under compressive stress states. In Sinha, N. K., D. S. Sodhi and J. S. Chung, eds. Proceedings of the Eighth International Conference on Offshore Mechanics and Arctic Engineering, The Hague, The Netherlands, March 19-23, 1989. Vol. IV. Arctic and polar technology. New York, American Society of Mechanical Engineers, 13-21.

Kalifa, P., G. Ouillon and P. Duval. 1992. Microcracking and the failure of polycrystalline ice under triaxial compression. f. Glaciol., $\mathbf{3 8}(128)$, 65-76.

Kemeny, J. M. and N. G. W. Cook. 1987. Crack models for the failure of rock under compression. In Desai, C. S. and others, eds. Constitutive laws for engineering materials: theory and applications. London, Elsevier, 879 887.

Murrell, S. A. F., P.R. Sammonds and M. A. Rist. 1991. Strength and failure modes of pure ice and multi-year sea ice under triaxial loading. In Jones, S., R. F. McKenna, J. Tillotson and I. Jordaan, eds. Ice-structure interaction. IUTAM-IAHR Symposium, St. Fohn's, Newfoundland, Canada, Aug. 14-17, 1989. Berlin, etc., SpringerVerlag, 339-361.

Paterson, M. S. 1978. Experimental rock deformation - the brittle field. Berlin, etc., Springer-Verlag.

Rist, M. A. and S. A. F. Murrell. 1991. Relationship between creep and fracture of ice. In Cocks, A. C. F. and A. R. S. Ponter, eds. Mechanics of creep-brittle materials. Vol. 2. London, Elsevier, 355-369.

Rist, M.A. and S.A.F. Murrell. 1994. Ice triaxial deformation and fracture. 7. Glaciol., 40(135), 305-318.

Sammis, C. G. and M. F. Ashby. 1986. The failure of brittle porous solids under compressive stress states. Acta Metall., 34, 511-526.

Sato, A. and G. Wakahama. 1980. Measurements of the velocity of crack propagation in ice. Low Temp. Sci., Ser. A 39, 193-195. [In Japanese.]

Scholz, C. H. 1990. The mechanics of earthquakes and faulting. Cambridge, Cambridge University Press.

Schulson, E. M., P.N. Lim and R. W. Lee. 1984. A brittle to ductile transition in ice under tension. Philos. Mag., Ser. A, 49(3), 353-363.

Sinha, N.K. 1984. Intercrystalline cracking, grain-boundary sliding, and delayed elasticity at high temperatures. f. Mater. Sci., 19(2), 359-376.

Stone, B. M., I.J. Jordan, S.J. Jones and R. F. McKenna. 1989. Damage of isotropic polycrystalline ice under moderate confining pressures. In Axelsson, K. B. E. and L. A. Fransson, eds. POAC 89 . The 10th International Conference on Port and Ocean Engineering under Arctic Conditions, June 12-16, Luleä, Sweden. Proceedings. Vol. 1. Luleå, Tekniska Högskolan i Luleå, 408-419.

Sunder, S.S. and M.S. Wu. 1990. Crack nucleation due to elastic anisotropy in polycrystalline ice. Cold Reg. Sci. Technol., 18 (1), 29-47.

Walsh, J. B. 1965. The effect of cracks on the uniaxial elastic compression of rocks. 7. Geophys. Res., 70 (2), 399-411.

Wawersik, W. R. and W.F. Brace. 1971. Post-failure behaviour of granite and diabase. Rock Mech., 3, 61-85.

The accuracy of references in the text and in this list is the responsibility of the authors, to whom queries should be addressed. 